\title{
Cerebral Meninges
}

National Cancer Institute

\section{Source}

National Cancer Institute. Cerebral Meninges. NCI Thesaurus. Code C12349.

The membranes that envelop and protect the brain. 